\title{
Un philosophe partage sa passion de l'alpinisme
}

\author{
Jean Martin \\ Dr med., membre de la rédaction
}

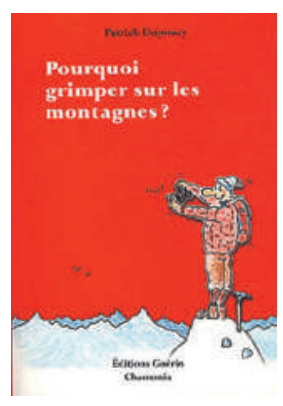

Patrick Dupouey Pourquoi grimper sur les montagnes?

Chamonix: Editions Guérin; 2012. 375 pages. $21.70 \mathrm{CHF}$. ISBN 978-2-35221-058-0
Patrick Dupouey est un enseignant de philosophie de 59 ans qui vit dans le Sud-Ouest de la France. Il publie un livre consacré à ce qu'il a vécu et appris en montagne en y pratiquant l'escalade - en particulier dans les Pyrénées dont il est proche. Qu'on n'attende pas un traité technique, même si l'on sent bien l'expérience pratique de l'auteur. Par contre, la philosophie et les philosophes y ont une bonne place. Les titres des 26 chapitres font référence à des thèmes attendus, par exemple danger, plaisir, beauté, silence et lumière, ou encore effort, risque, courage et vertige. Mais on relève que l'auteur consacre trois chapitres successifs à trois vocables particuliers: architecture, matière et "sommités»-discutant à chaque fois une dimension particulière.

Pourquoi la montagne et l'escalade? George Mallory, un des premiers à s'attaquer à l'Everest, y disparut le 8 juin 1924 (nul ne sait s'il est mort avant d'atteindre la cime ou après y être arrivé). A la question de pourquoi il tenait tant à le gravir, il répondait: "Parce qu'il est là.» Cela vaut, dit Dupouey, pour toutes les montagnes, parmi de nombreux autres motifs. Ainsi ce mot de Henry Russell, à l'aube d'une ascension: "C'était une matinée à donner aux saints la nostalgie de la terre.» Et l'éloignement du monde: «La joie du sommet c'est aussi de voir où l'on n'est pas, d'où l'on vient et où il faudra bientôt redescendre: la ville, le bruit, l'agitation, les soucis.» Aussi, à l'époque du GPS et de l'iPhone: "Pouvoir se perdre sera bientôt le vrai luxe.»

«Le monde du randonneur naît de la tension et même de la douleur ressentie dans les mollets; celui du grimpeur des équilibres sentis sur les prises et de l'effort pour s'arracher à la pesanteur. Ces actes physiques font littéralement exister la réalité. L'effort du montagnard fait être la montagne.»

Désir, prudence, témérité, décisions à assumer. «Le récit d'un ami, la lecture d'une carte, voire une simple photo, suffisent à faire naître un désir d'ascension. Souvent même on en restera au désir, et pas moins heureux pour cela.» «Il y a une intelligence du chemin et de la voie d'escalade, mise en œuvre par l'instinct de ceux qui les ont tracés. Ici comme ailleurs, l'intelligence c'est l'adaptation, la souplesse, donc aussi ruse et procédés détournés. La bêtise est de vouloir conclure le plus vite pos- sible et pour cela d'aller tout droit» - formule qui à l'évidence ne s'applique pas qu'à la course en montagne. «Avec la peur, les choses se compliquent du fait qu'il y a des choix à faire. Il faut peser, délibérer, ensuite arrêter un choix. Enfin s'en féliciter ou s'en repentir. La lâcheté devant l'obstacle peut appeler à la rescousse la saine prudence, mais l'amour propre sait bien s'allier contre la prudence avec d'autres éléments [...]. Tous les alpinistes savent que le plus difficile est de renoncer.» Il cite ici Spinoza: «Fuir à temps et combattre témoignent de la même fermeté d'âme.»

«Il y a pour s'engager et donc s'exposer au danger d'autres motifs qu'une fascination malsaine pour la mort. Au premier rang de ces motifs figure la société contemporaine, les valeurs qu'elle promeut et celles qu'elle abaisse. Nietzsche écrivait 'On adore aujourd'hui la sécurité comme la divinité suprême'. Cette religion sécuritaire n’a cessé de gagner du terrain.» Pratiquer l'escalade est une manière de s'en distancer.

Silence. «Le silence ouvre à mille détails auxquels le solitaire est plus disponible. La vigilance s'en trouve accrue et la méditation enrichie [...]. La solitude offre à l'homme un double avantage: le premier d'être avec soi-même, le second, de n'être pas avec les autres.» Citation de Rousseau: «Partout où il y a des hommes, je suis chez mes frères, partout où il n'y en a pas, je suis chez moi.» Dupouey sur aujourd'hui: «La valeur d'une civilisation pourrait bien se mesurer à la dose de silence qu'elle est capable de supporter. Inquiétant d'entendre des adolescents dire que tout silence leur pèse. Allons dans les montagnes pour tenter d'écouter ce qu'il y a de meilleur en nous.»

Des choix, en sachant qu'il y en a d'autres. "C'est par l'effort que ce qu'on fait plaît. Les actions et conquêtes que permet la montagne sont à prendre ou à laisser, comme nous laissons à d'autres la navigation ou le jeu d'échecs. Ceux qui ont pris le chemin des montagnes y tiennent, au détriment de mille découvertes à faire, de mille choses à apprendre... qui valent autant et sans doute, pour certaines, davantage.» Ceux qui ont fait le choix de la montagne peuvent aussi se souvenir de Montaigne écrivant: "Au plus élevé trône du monde, nous ne sommes assis que sur notre cul.» 